\title{
An Overview of Entrepreneurship, Innovation and Sensemaking for Improving Decisions
}

\author{
Domingo Ribeiro-Soriano' ${ }^{1}$ - Sascha Kraus ${ }^{2}$
}

Published online: 27 March 2018

(C) Springer Science+Business Media B.V., part of Springer Nature 2018

\section{Introduction}

The complexity, turbulence and rate of change of the business environment have intensified in recent decades (Ribeiro-Soriano and Urbano 2009). At the same time, small business owners and entrepreneurs have received greater recognition as drivers of economic growth. Several studies (Forsman 2011; McKeever et al. 2014) have reported that long-term economic growth and prosperity require participation from entrepreneurs. Both experts and government authorities seek to foster entrepreneurship as "an appropriate mechanism to face the impacts of the economic crisis" (GEM 2014, p. 100).

Entrepreneurship is increasingly considered a milestone on the road towards progress (Semrau et al. 2016). It contributes to countries' development and prosperity and helps nations cope with growing environmental complexity (Welbourne and Pardodel-Val 2009). As a key driver of economic regeneration and growth, entrepreneurship receives considerable attention (Ferreira et al. 2017). Entrepreneurs identify and solve problems, which at the same time provide opportunities (Lee et al. 2009; Craig et al. 2014). In today's environment, entrepreneurship encourages the competition that is necessary to reap the rewards of globalisation. One of the pillars of entrepreneurship is innovation (Eckhardt and Shane 2003; Reschke and Kraus 2008). In the knowledge era, an effective way for countries to gain a competitive advantage is through con-

\footnotetext{
$凶$ Sascha Kraus

sascha.kraus@esce.fr

Domingo Ribeiro-Soriano

domingo.ribeiro@uv.es

1 Universitat de València, Valencia, Spain

2 École Supérieure du Commerce Extérieur, ESCE International Business School, Paris, France
} 
tinual technological innovation. Innovation is thus a key source of knowledge-based competitive advantage (Jensen et al. 2010).

The ability to innovate in technology aids knowledge development. But what form will the trend take in the coming years? And how should researchers link entrepreneurship and innovation to decision-making? Here, we examine relationships stemming from best practices and routines that support decision-making and negotiation processes in groups and societies. The related multidisciplinary activity of innovation has attracted much attention from scholars. Innovation is about planting the seeds for new opportunities to flourish and create value, enabling entrepreneurs to discover, assess and harvest their creative efforts (Shane and Venkataraman 2000; Eggers et al. 2014). Sensemaking, on the other hand, involves "turning circumstances into a situation that is comprehended explicitly in words and that serves as a springboard into action" (Weick et al. 2005, p. 2). Entrepreneurship performance relates not only to innovation but also to entrepreneurs' ability to match their capabilities to their context using persuasive sensemaking devices that lend coherence to decisions and negotiation (Lounsbury and Glynn 2001; Holt and Macpherson 2010). Negotiation is a general form of social interaction that is necessary whenever conflict arises and there are no fixed procedures to resolve that conflict. To reduce opportunistic behaviour in the negotiation and decision-making process, the other members of the team must share the entrepreneur's values. In other words, the entrepreneur and his or her team must have common goals, a common vision and coherent strategies (Schjoedt and Kraus 2009).

Theories, methods and applications are the three pillars that allow researchers to tackle the big questions in entrepreneurship and innovation. Each theory acts as a lens that allows scholars to interpret a certain form of entrepreneurship and innovation, identify a particular set of problems and seek a range of solutions to these problems. Hence, critically reviewing these theories and analysing the resulting practices is crucial. Scholars who consolidate and apply these theories use different methods and approaches to contribute and question the implications and even the fundamental premises that support these theories. The following are examples of empirical studies or cases that fit within this Special Issue: using sensemaking as a tool in the decisionmaking processes of innovative companies, identifying innovative implementations that can improve decision-making during firm creation and boosting entrepreneurial performance by innovating through sensemaking in the decision-making process.

To break new scholarly ground and enrich our understanding of how entrepreneurship, innovation and sensemaking can improve decisions, this special issue presents contributions that focus on different areas of analysis. The aim of this Group Decision and Negotiation Special Issue is therefore to provide theoretical and empirical evidence that links entrepreneurship and innovation to decisions, using a wide array of rigorous quantitative and qualitative methods, conceptual papers that explore different theoretical perspectives and articles that offer multiple levels of analysis. This focus also emphasises the connections amongst the entities involved in group decision support activities. Thus, the articles in this special issue not only align with the journal's overall focus on relations and coordination in group processes by exploring the entire process or flow of activities in group decision and negotiation, but also apply the specific lens of entrepreneurship and innovation to investigate this context. 
To reflect the pressing need for new, promising ideas in this area, we have deliberately opted for a broad mix of contributions.

\section{Contributions}

"The Price of Team Spirit for Sensemaking through Task Discourse in Innovation Teams" explains how innovation teams can benefit from their different task understandings and perspectives. This issue is highly relevant because teams often balk when they realise their extended problem solving and creativity potential. The primary challenge for teams is to understand, question and integrate the full range of team members' perspectives. Ratzmann, Pesch, Bouncken and Martínez-Climent introduce task discourse to make sense of teams' inherent ambiguity. Task discourse is the open, constructive discussion of task understanding, task completion and problem solving. It enables team members to challenge and consolidate different perspectives. The present study not only describes how task discourse improves team performance by helping team members use different perspectives effectively, but also elaborates on how team creativity and feasibility testing stimulate task discourse. The study is based on data from a sample of 250 innovation teams in the German manufacturing industry. The results indicate that team creativity is positively related to task discourse, which is in turn positively related to team performance. An in-depth understanding of sensemaking in teams requires the consideration of contextual factors because task discourse is embedded in the social-affective team environment. The authors discuss team spirit as a crucial contextual factor of task discourse. They elaborate on ambivalent effects in innovation teams. By providing a sense of group togetherness, team spirit can improve team climate, interaction and communication processes, and team performance. However, team spirit can also lower an individual's willingness to challenge different perspectives to avoid tensions for the sake of unity. The study's empirical results support this assumption regarding team spirit as a double-edged sword. Although team spirit is positively related to team performance, the interplay between task discourse and team spirit is negative. The study's results also indicate that team size is another important contextual factor, shaping the negative interplay between task discourse and team spirit. The authors make two important theoretical contributions. First, the authors enrich research on sensemaking by introducing task discourse as a valuable sensemaking mechanism in teams. Scholars have highlighted the importance of sensemaking for innovation and the antecedents and outcomes of team sensemaking but have neglected the underlying sensemaking processes. Second, the authors extend the social cognition approach that conceptualises aspects of human information processing - specifically, the role of mental processes when people interact with one another. The authors address how social context influences sensemaking in teams by considering team spirit and team size as contextual factors of task discourse. The study's findings should stimulate further research on team sensemaking.

In "A Review about the Role of Negotiation in Open Innovation", Barchi and Greco present a systematic literature review to fill the gap in research on the organic analysis of the role of negotiation within the open innovation paradigm. The literature review describes the state of the art of negotiation from the open innovation perspec- 
tive through the identification of several frameworks, theories and decision support systems, which are classified into three categories: preparation of negotiations, conduction of negotiations and general. This article deals with the relationship between the decision processes that underlie negotiations and the innovativeness of firms and groups of firms. The goal is to support practitioners to leverage the effectiveness of the open innovation paradigm. Many articles cannot be classified according to the basis of the two fundamental steps of negotiation (preparation and conduction), so the authors classify them into four sub-sections: frameworks, intellectual property, absorptive and desorptive capacity, and corporate culture. The analysis presented in the literature review confirms the complexity of negotiation in inter-organisational interactions from the open innovation perspective. Despite the difficulty in communicating and handling negotiations when dealing with cultural and managerial heterogeneity, the suitable management of intellectual property and decision rights is an important issue and requires the negotiation of agreements throughout the entire life cycle of a collaborative project. The article highlights the intense complexity in organisations that, despite embracing open innovation, are unprepared for radical cultural change. In these cases, negotiation is far from simple. These organisations are forced to act in several directions, including towards the outside of the organisation, within the organisation and further inwards. The authors conclude that negotiation in open innovation requires a continuous focus on the human side. The article stresses the importance of negotiation and the need for a clearly defined structure in a process led by top managers who use modern technological support to increase effectiveness and efficiency. If the necessary competencies to manage such complex negotiations are missing, intermediary services can help.

In "Learning Orientation and Performance Satisfaction as Predictors of Small Firm Innovation: The Moderating Role of Gender", Mahto, McDowell, Kudlats and Dunne empirically examine the roles of learning orientation, the underlying values of firms regarding learning and skill development, and owner-managers' performance satisfaction with innovation or risk-taking initiatives of the firm. The authors also posit that these relationships are moderated by the gender of the owner-manager, predicting that female owners experience a weaker relationship between learning orientation and innovation and between performance satisfaction and innovation than their male counterparts do. Analysis of data from a survey of 300 small business owners shows a significant positive relationship between learning orientation and innovation but fails to show a significant relationship between performance satisfaction and innovation. Surprisingly, gender has a partially significant effect on learning orientation and innovation, but this effect is positive rather than negative. The results of this study confirm that learning orientation, regardless of the owner-manager's gender, is important for small firms that seek to gain a competitive advantage through innovation and that firms should strategically implement mechanisms for greater learning to achieve these desired results.

In 'Inspired or Foolish: Confidence and Entrepreneurs' Decision Making”, Cunningham and Anderson investigate the role of confidence in the way that new and experienced entrepreneurs interpret their business environment and make decisions. The study uses data from a large-scale survey that collected 6289 entrepreneurs' perceptions of business performance and these entrepreneurs' decisions during a period 
of economic downturn. Quantitative and qualitative findings show the heterogeneity of entrepreneurial decision-making and explain the role of confidence, respectively. This article does not directly examine the confidence of the individual but instead studies how this confidence affects decision-making. Overall, the study contributes to our understanding of how entrepreneurial attitudes change with experience by comparing and contrasting business actions and perspectives at various levels of entrepreneurial experience. Primary findings highlight that newer entrepreneurs are more optimistic in the face of environmental risk and are therefore more reluctant to change their organisational set-up. In contrast, experienced entrepreneurs warily look to maintain their margins and restructure to adapt to environmental change. The article explains this difference in confidence in terms of the difference in the environmental situations that new and experienced entrepreneurs face. New entrepreneurs face great uncertainty in almost all business areas: resources, liabilities, weaker ties with suppliers and customers and overall lack of experience. Therefore, although the extent of this confidence can be seen as inappropriate during the recession, to confront this uncertainty, entrepreneurs must be confident. Although this confidence often leads to non-rational confidence and biased decision-making, a completely rational approach, void of optimism and confidence, may not lead to a start-up at all. The authors conclude that the primary focus of new entrepreneurs on increasing sales through dramatic price reductions, rather than reducing costs, suggests that they have greater confidence in their set-up and operational configurations than more established firms do. New entrepreneurs remain more optimistic about improvements in the near future, despite dips in trade due to the recession. However, one explanation for this optimism is that new entrepreneurs do not have the weight of previous performance comparisons on their shoulders. In contrast, more experienced entrepreneurs take a more defensive stance, consolidating and retrenching to adapt to the downturn by restructuring their operational set-up. Accordingly, both groups of entrepreneurs make sense of themselves and their environment in different ways. A further conclusion is that new entrepreneurs also perceive risk differently from the way that more experienced entrepreneurs do. New entrepreneurs make brazenly confident decisions to survive, exposing themselves to failure. The implication is that as entrepreneurs develop and gain experience from environmental volatility, they develop a more realistic view of the market and therefore make decisions that are better aligned with market demand. However, experienced entrepreneurs' conservatism regarding risk may limit growth and innovation.

In "Organizing for commons-enabling decision making under conflicting institutional logics in social entrepreneurship", Rossignoli, Ricciardi and Bonomi explore sense-making and decision-making issues in social entrepreneurship, a context that has thus far been overlooked by decision and negotiation sciences (Mair et al. 2012). Social entrepreneurs (individual or collective) must reconcile two seemingly incompatible goals: developing self-sustaining business models like commercial entrepreneurs whilst pursuing the common good as their primary goal. Therefore, social entrepreneurship initiatives (such as micro-financing, low-cost healthcare services for developing countries and work integration) are subject to idiosyncratic complexities and contradictions. It is therefore increasingly clear that we cannot borrow well-established decision-making approaches and techniques from other contexts. 
Instead, specific models and tools are needed to understand and support decisionmaking processes in social entrepreneurship. Rossignoli, Ricciardi and Bonomi argue that two key aspects must be considered to understand the specific difficulties that affect decision-making in social entrepreneurship. First, in social entrepreneurship, at least one commons (such as clean air, public health and people's employability) is usually at stake. Therefore, the typical social dilemmas triggered by commons-related choices may jeopardise the initiative, unless these social dilemmas are understood and controlled (Dietz et al. 2003). Second, social entrepreneurship typically develops networked business models that are based on distributed activity systems that involve different actors beyond traditional organisational boundaries. Therefore, social entrepreneurship requires cooperation across fragmented organisational fields that probably operate under conflicting institutional logics (Pache and Santos 2010). The authors use the literature on the commons and institutional logics to identify five key strategies to protect the relevant commons and manage the relevant conflicting logics in social entrepreneurship. These are network-level self-regulation, transparency, nested institutions, effective management of environmental uncertainty and the build-up of a common ground. Through inductive analysis of a longitudinal case, the authors investigate how a successful social entrepreneurship initiative uses these strategies to create the organisational conditions for decision-making processes that foster the commons that lie at the core of any social enterprise's mission. The results confirm the importance of the five aforementioned strategies. The study shows that the social entrepreneur introduces a bridging organisation in a previously fragmented organisational field, thus transforming it into an integrated, boundary-spanning activity system. This bridging organisation develops an innovative co-creation logic, which serves as a common ground that enables collaboration between actors, even if these actors are influenced by diverse and even conflicting institutional logics. In addition, the longitudinal analysis reveals that a disclosure-driven path (based on classical conflict analysis techniques) is not the best way to construct such a common ground. Instead, a practice-driven path allows for better management of ideological polarisations. Finally, the analysis reveals the importance of an ICT-enabled resource management system. This tool adds collaboration and traceability to a previously opaque context and is critical for creating the conditions for new decision-making processes at the organisational field level that protect and develop the commons that is at stake.

Lastly, in "Women Entrepreneurs and Family Firm Heterogeneity: Evidence from an Emerging Economy", Welsh, Kaciak, Trimi and Wagner Mainardes examine the heterogeneity of women-owned family firms in a developing country (Brazil). The study explores the relationships between key factors such as firm performance, family involvement and the financial resources at the start-up phase. The authors investigate the current practices of family firms and women entrepreneurs by formulating propositions. This study focuses specifically on women entrepreneurship because despite the increasing involvement of women in family business and the widespread acceptance of their importance for economic growth, innovation and job creation worldwide, the heterogeneity of women entrepreneurs has been under-investigated. This study thereby fills a gap in the literature. The study also contributes by focusing on Brazil, an emerging economy whose cultural perspective is based on high levels 
of "masculinity". Two of the primary factors that shape women-led entrepreneurial processes are family involvement and resources. These dimensions are investigated in relation to firm performance. Family involvement is investigated through its organisational role in women entrepreneurs' start-ups. Firm resources are categorised into their corresponding forms of capital. The study focuses on physical capital, which is defined as "access to financial resources during the start-up phase". The study yields various findings. First, firms that are owned and managed by Brazilian women entrepreneurs and that were started with the family and have been kept as family businesses perform better than firms that are now family firms but began without family involvement. Second, firms that were started without family involvement and that later evolved into family firms perform worse than firms that were kept separate from family involvement. Third, it is better for the business to be funded using investment from the family or others rather than women entrepreneurs' own savings. The results remain useful for decision-making by women entrepreneurs who work in emerging economies and who currently own family businesses or who are contemplating involving their families in a formerly non-family business. Furthermore, the study can also help governments create policies to promote women entrepreneurship by showing that these policies should not simply consider family firms as a homogeneous group.

\section{References}

Craig JB, Pohjola M, Kraus S, Jensen SH (2014) Exploring relationships among proactiveness, risk-taking and innovation output in family and non-family firms. Creat Innov Manag 23(2):199-210

Dietz T, Ostrom E, Stern PC (2003) The struggle to govern the commons. Science 302:1907-1912

Eckhardt JT, Shane SA (2003) Opportunities and entrepreneurship. J Manag 29:333-349

Eggers F, Kraus S, Covin J (2014) Traveling into unexplored territory: pioneering innovativeness and the role of networking, customers, and turbulent environments. Ind Mark Manag 43(8):1385-1393

Ferreira JJM, Fernandes CI, Kraus S (2017) Entrepreneurship research: mapping intellectual structures and research trends. Rev Manag Sci. https://doi.org/10.1007/s11846-017-0242-3

Forsman H (2011) Innovation capacity and innovation development in small enterprises. A comparison between the manufacturing and service sectors. Res Policy 40:739-750

GEM (Global Entrepreneurship Monitor) (2014) Informe GEM España 2013 [GEM Spain Report 2013]. Red Española de Equipos Regionales [Spanish Network of Regional Teams]. http://www.gemconsortium. org/

Holt R, Macpherson A (2010) Sensemaking, rhetoric and the socially competent entrepreneur. Int Small Bus J 28:20-42

Jensen SH, Poulfelt F, Kraus S (2010) Managerial routines in professional service firms: transforming knowledge into competitive advantages. Serv Ind J 30:2045-2062

Lee SM, Lim S-B, Soriano DR (2009) Suppliers' participation in a single buyer electronic market. Group Decis Negot 18:449-465

Lounsbury M, Glynn MA (2001) Cultural entrepreneurship: stories, legitimacy, and the acquisition of resources. Strateg Manag J 22:545-564

Mair J, Battilana J, Cardenas J (2012) Organizing for society: a typology of social entrepreneuring models. J Bus Ethics 111:353-373

McKeever E, Anderson A, Jack S (2014) Entrepreneurship and mutuality: social capital in processes and practices. Entrep Reg Dev 26:453-477

Pache AC, Santos F (2010) When worlds collide: the internal dynamics of organizational responses to conflicting institutional demands. Acad Manag Rev 35:455-476 
Reschke CH, Kraus S (2008) Strategy, innovation and entrepreneurship — an evolutionary learning perspective. In: Hanappi H, Elsner W (eds) Advances in evolutionary institutional economics-evolutionary mechanisms, non-knowledge and strategy. Edward Elgar, Broadheath, pp 189-216

Ribeiro-Soriano D, Urbano D (2009) Overview of collaborative entrepreneurship: an integrated approach between business decisions and negotiations. Group Decis Negot 18:419-430

Schjoedt L, Kraus S (2009) Entrepreneurial teams: definition and performance factors. Manag Res News 32:513-524

Semrau T, Ambos TC, Kraus S (2016) Entrepreneurial orientation and SME performance across societal cultures. J Bus Res 69(5):1928-1932

Shane S, Venkataraman S (2000) The promise of entrepreneurship as a field of research. Acad Manag Rev 25:217-226

Weick KE, Sutcliffe KM, Obstfeld D (2005) Organizing and the process of sensemaking. Organ Sci 16:409-421

Welbourne TM, Pardo-del-Val M (2009) Relational capital: strategic advantage for small and medium-size enterprises (SMEs) through negotiation and collaboration. Group Decis Negot 18:483-497 